\title{
Pharmacoeconomic Analysis of the Therapies Used in the Treatment of Smoking in a Specialized Unit
}

Pedro J Tarraga Lopez*, Raul Grdoy, Francisco Javier Callejas, Ana I Tornero, Jose Antonio Rodriguez Montes, Angel Molina and Denis Oriot

Health Service of Castilla-La Mancha Albacete, Albacete, Spain

\begin{abstract}
Objective: Cost-effectiveness analysis of the major tobacco control tools medium long term.

Method: This is a retrospective, descriptive study of the results obtained after analyzing the sample of all patients who attended the Unit Specialized Treatment Smoking during two years. Without drug treatment: the costs and effectiveness of the four options used in our Unit for smoking cessation compared: 1) Bupropion+ NRT, 2) Varenicline, 3) Varenicline and NRT and 4) No pharmacology treatment.

Costs and efficiency: Efficiencies rates for comparison are the result of our study for the 4 options. All costs are expressed in euros, both costs and an effect beyond the first year rate of $3.5 \%$ per annum is deducted. 1.4. Results: Of the 559 patients, $32.7 \%$ received no treatment. $34.5 \%(n=194)$ of patients was treated with NRT (gum, patches or in combination with varenicline). Varenicline is the second most frequently used drug with $22.9 \%$ and, finally, bupropion $(9.8 \%)$. The analysis results show that the greater efficacy of varenicline is a better cost/effectiveness (C/E) in the treatment of smoking medium to long term that comes to fully offset the higher cost of treatment compared to the other options. So both varenicline monotherapy as associated with TSN have average costs of $€ 2.491,21$ and $€ 2.432,22$ per patient who quit smoking compared to the other options with Bupropion and TSN 4.136,55€ or drug treatment to $5.783,88 €$ in a perspective of two years.
\end{abstract}

Conclusion: The option of giving Varenicline is a better cost/effectiveness $(C / E)$ in the treatment of smoking-half longer than the other options.

Keywords: Tobacco; Costefectiveness; Varenicline; Bupropion

\section{Introduction}

The tobacco is the first single cause of premature death in socioeconomically advanced countries [1], is a health problem with a high cost in premature and preventable deaths, preventable disease and disability, and unnecessary suffering. Secondly, all this has very high economic costs, consuming resources that otherwise could be spent for other purposes $[2,3]$.

In Spain, smoking consumes $15 \%$ of their health expenditure, approximately 15,000 million euros. The National Committee for Smoking Prevention (NPTC) of Spain has said that of the nearly 10,000 million euros in annual health budget, adding the public and the private, around $15 \%$ is related to the diagnosis and treatment of diseases linked to consumption of snuff $[4,5]$.

The pathology is in first place is coronary disease, whose health costs in 2009 amounted to over 3,600 million euros. Followed by chronic obstructive pulmonary disease (COPD), with nearly 3,000 million euros. This condition affects $33 \%$ of smokers and therefore $20 \%$ of adults over 65 years. The greater the distance appear disorders Cerebrovascular with 710 million euros of spending, asthma (267 million euros) and lung cancer (163 million euros). This figure does not include the 530 million estimated passive smoking caused.

Another cost of smoking constitutes lost productivity at work. The public and private sector figure this amount 6,720 million euros. Absenteeism linked directly or indirectly to snuff consumption is estimated at approximately 250 million euros. The costs of facilities, cleaning and maintenance from the consumption of snuff are around 1,800 million euros [5-8].

Moreover, the comparative smoking prevention in our performance is very high: getting a patient 20 years quit smoking have a performance life expectancy three times higher than control their hypertension, and almost ten times higher to control their cholesterol [2]. Therefore, control of smoking should be one of the largest health priorities 9-10. The main problems are twofold. On the one hand, protect young people (particularly women today) and help them not to start smoking. On the other, help smokers who want him to quit. As we will see progress on this second problem they make it easier to deal with the first. Protection of adolescents is a priority, and raises the greater social consensus. However, it is the most difficult, because it leads to deal directly with the promotional efforts of the tobacco industry, which needs to recruit new addicts to replace those who die or leave the habit [8-12].

The other priority is to facilitate quitting the vast majority of smokers who want it. This objective collides with the objective fact that nicotine addiction Manuscriptis very intense. Moreover, in our population of smokers, there are many who are in the phase called pre-contemplation, needing a trigger to initiate a cessation attempt. However, many doctors do not have the time, skills or motivation to make this effort. A recent review of the Programme of Preventive Activities and Health Promotion documented that many health centers are active in this field, but the proportion of patients consisting signs of intervention is lower than for other risk factors [12-14]. This same study showed that $7.6 \%$ of the recommended smokers quit smoking, a result of the program that is all very favorable when compared with

*Corresponding author: Pedro J Tarraga Lopez, Health Service of Castilla-La Mancha Albacete, Albacete, Spain, Tel: 34609080627; Fax: 3467225533; E-mail: pjtarraga@sescam.jccm.es

Received April 24, 2016; Accepted May 13, 2016; Published May 16, 2016

Citation: Lopez PJT, Grdoy R, Callejas FJ, Tornero AI, Montes JAR, et al. (2016) Pharmacoeconomic Analysis of the Therapies Used in the Treatment of Smoking in a Specialized Unit. J Pulm Respir Med 6: 347. doi:10.4172/2161-105X.1000347

Copyright: @ 2016 Lopez PJT, et al. This is an open-access article distributed under the terms of the Creative Commons Attribution License, which permits unrestricted use, distribution, and reproduction in any medium, provided the original author and source are credited. 
5\% might be expected according to studies iniciales 12 modes. Drug treatment and other specialized options can help a selected group of patients, who are at greater risk. Although requiring more intensive support is a relatively small fraction of total smokers, the potential benefits to help them age [15].

In recent years we have progressed: Ten years ago, smokers in the survey said that nobody advised them to quit, while half now tell us that your doctor has dicho15. But we have much to do and we know that many professionals do not take an active role: in fact smokers know that doctors often do not, and we still have $32 \%$ of smoking physicians [14-17].

In Spain there are various drug therapies support the smoker who have shown their effectiveness, so far pharmacological options available in our country are essentially replacement therapy nicotine (TSN) in various forms of administration (gum, patch), the bupropion, an inhibitor of the reuptake of norepinephrine and serotonin has been effective although its mechanism of action is still unclear and there are clear contraindications for use related to the existence of psychicanorexia problems nervous, convulsive disorder, bipolar disorder, etc. and drug varenicline tartrate partial agonist for nicotine receptors alpha4 beta2 indicated in the treatment of tabaquismo [17-19].

The objective of this analysis is to analyze the cost-effectiveness relationship between the costs and the effect of these anti-smoking tools medium long term.

\section{Method}

The organization responsible for providing universal free health care proclaiming the Spanish law is the Health Service of Castilla La Mancha (SESCAM).

This is a retrospective, descriptive study of the results obtained after analyzing the sample of all patients who attended the Unit Specialized Treatment Smoking University Hospital of Albacete from 1 January 2008 until 31 December 2009 and its follow-up to complete a year.

Patients who access our consultation are derived either by a specialist or by your primary care physician also they serve on our medical staff of the hospital consultation that demand support for smoking cessation. These patients reflect the characteristics of the smoking adult population.

Monitoring patients consists of:

\section{First visit}

All patients included in the consultation, a general medical history, a specific history of smoking which reflects current consumption of cigarettes (including type of snuff) and its variations since the beginning of consumption is contemplating the age of onset, the number of previous attempts to quit, eventually achieved abstinence in those attempts and the reason for relapse and if they have previously received any treatment or support to quit smoking. It is also reflected in medical history if they live with smokers in their family, social or work environment. their motivation is considered important to stop smoking and what is the benefit expected from consumer abandonment physical examination with making constant, performing co-oximetry, test Fagerström nicotine dependence test motivation and Richmond, and request additional examinations that are created appropriate, as well as other specialists interconsultations is performed if necessary. The intensity of dependence is reflected by results of Test Fagerström and abandonment phase in which the patient is (pre-contemplation, contemplation, preparation, action, maintenance and relapse on the mode of Prochaska and DiClemente) fixed the day of quitting if the patient is ready.

The patient to perform self-monitoring cigarettes are requested and decide whether treatment is to be performed individually or in group (currently all treatment is set individually), giving in this case the visitation schedule already established, and the election drug treatment if it is to be used, which is selected according to the number of cigarettes smoked, the test of nicotine dependence, the co-oximetry, patient comorbidity, contraindications and drug interactions and, of course, preferences the patient whenever possible, explaining both the side effects of drugs and the rules for its use.

\section{Second visit}

The day before it is performed at the time of abandonment: it is checked whether it has begun with the fall in consumption, registration of cigarettes, and if they had already begun drug treatment, checked their correct use and the presence or absence of side effects attributable to the drug. If you have not started drug treatment you are given treatment guidelines in writing to start the day of abandonment. Symptoms of withdrawal are valued,

\section{Successive visits}

Three fifteen days after the date of abandonment are scheduled, performing measurement of withdrawal symptoms, co-oximetry, troubleshooting and monitoring of correct treatment compliance and possible side effects.

Successive visits are made according to evolution, availability and patient needs at least once a month until they complete drug treatment or three months of abstinence are met, performing controls at 6 and 12 months.

During these visits relapse prevention strategies, measurement of withdrawal, co-oximetry and troubleshooting syndrome are made. All patients have access to a phone contact for problem solving

All patients are given the phone consultation if they decided to try again in case of relapse.

This study has the approval of the Ethics Committee for Clinical Research of Integrated Management of Albacete.

\section{Statistical analysis}

As a tool for performing database SPSS version 18 on Windows Vista operating system with the results thereof was used, as well as data provided by the Service of Pneumology of the Hospital Universitario de Albacete and includes the following hospitals: Hospital General Universitario de Albacete, Albacete Perpetuo Socorro Hospital, General Hospital of Villarrobledo and Almansa General Hospital.

For quantitative variables were used measures central tendency (mean, median), measures of position (quartiles) and dispersion (standard deviation or range interquartílico).

The relationship between two qualitative variables were calculated from Chi-Square test () or Fisher exact test (if in any case the observed frequency was $<5$ ). For ordinal variables linear trend through coefficient Kendall Tau-c was determined.

Quantitative variables were compared using the Student $\mathrm{t}$ test ( $<2$ categories) and ANOVA (in the case of variables $>2$ categories), linear trend test and test of multiple comparisons (Scheffe). The linear relationship between quantitative variables through Pearson correlation test or Spearman was determined (if the variable is not normally 
distributed).

For all tests have determined a significant difference from a $\mathrm{p}<0.05$.

\section{Pharmacoeconomic study}

Costs and effectiveness of the four options used in our Unit for smoking cessation are compared (Table 1): 1) No drug treatment, 2) Bupropion + NRT, 3) Varenicline, 4) Varenicline and NRT.

\section{Costs and efficiency}

The costs were calculated for the costs of the drugs and calculating office hours the physician performing the treatment for smoking cessation. Efficiencies rates for comparison are the result of our study for the 4 options.

Perspective, time horizon and discount: The analysis is done from the perspective of the National Health System valuing all direct costs and health effects of treatments using the temporary effect of the duration of the study. All costs are expressed in euros, both costs and an effect beyond the first year rate of $3.5 \%$ per annum is deducted.

\section{Results}

From 1 January 2008 until 31 December 2009 were referred to our clinic 838 patients, of which only 559 attended, $53.7 \%(n=300)$ were male and $46.3 \%(n=259)$ women. The average age of the sample was 46.18 years (range 18-79 years), the average age of smoking initiation of 17.15 years (range $8-36$ years) and the average consumption exceeds the daily cigarette packet cigarettes per day 27, 30.

Before starting treatment decided to leave $49.7 \%$ (Figure 1).

Of the 559 patients, $32.7 \%$ received no treatment. $34.5 \%(n=194)$ of patients was treated with NRT (gum, patches or in combination with varenicline). Varenicline is the second most frequently used drug with $22.9 \%$ and, finally, bupropion (9.8\%). In the Table 2 shown a description of all treatments and the doses used.

Frequency and percentage of patients, who relapsed during treatment,

- $\quad$ During the first week: 17 patients (3\%).

- Between the first week and first month (before 30 days): 41 patients (7.3\%).

- Between the first and third month (before 90 days): 67 patients (12\%).

- Between the third and sixth months (180 days before): 28 patients (5\%).

- Between the sixth month and year (365 days before): 8 patients (1.4\%).

In Table 3 the percentage of patients having a continuous abstinence treatment depending on the received reflected. The highest percentage of success was given when treatment with Varenicline (VRN) or

\begin{tabular}{|c|c|c|c|c|}
\hline & Varenicline & Bupropión & NRT & $\begin{array}{c}\text { No treatment } \\
\text { pharmacology }\end{array}$ \\
\hline $\begin{array}{c}\text { Treatment } \\
\text { Cost }\end{array}$ & 361,68 & 154,42 & 155,28 & 0 \\
\hline $\begin{array}{c}\text { Cost Medical } \\
\text { Visit }\end{array}$ & 32,42 & 32,42 & 32,42 & 32,42 \\
\hline \multicolumn{4}{|c|}{ Table 1: Cost parameters. } \\
\hline \multicolumn{4}{|c|}{}
\end{tabular}

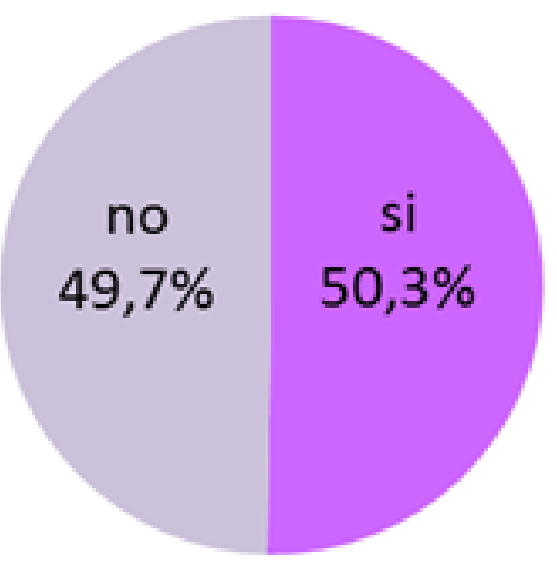

Figure 1: Withdrawals before starting treatment.

\begin{tabular}{|c|r|c|}
\hline Treatment & & \\
\hline None & 183 & $32.7 \%$ \\
\hline Bupropion & 55 & $9.8 \%$ \\
\hline Varenicline & 126 & $22.9 \%$ \\
\hline NRT/Varenicline & 195 & $34.5 \%$ \\
\hline
\end{tabular}

Table 2: Pharmacological treatment used.

\begin{tabular}{|c|c|c|c|c|}
\hline & No treatment & NRT y Bup & Varenicline & VRN y NRT \\
\hline No & $95.5 \%$ & $85.6 \%$ & $74 \%$ & $66.7 \%$ \\
\hline Yes & $4.5 \%$ & $14.5 \%$ & $26 \%$ & $33.3 \%$ \\
\hline
\end{tabular}

Table 3: Success (\%) according to the treatment used.

combination therapy with VRN and NRT (33\%).

The test $\mathrm{Z}$ only found statistical difference for Varenicline (26\%) compared to no treatment (4.4\%), with $99 \%$ confidence, and for NRT and Bupropion (14.5\%) compared to no treatment, with $96 \%$ confidence, so it is possible that the large percentage of success with $\mathrm{NRT}+\mathrm{VRN}$ and is due to chance.

Correlation was also found with Chi-square test (99\% confidence), with a strength of correlation of 0.232 according to the test Cramer's V, and a regression model whose odds ratios indicate that it is always more likely to have built successful treatment of VRN and NRT, followed by varenicline. In Table 4 its shows Pharmacoeconomic Analysis.

The analysis results show that the greater efficacy of varenicline is a better cost/effectiveness $(\mathrm{C} / \mathrm{E})$ in the treatment of smoking medium to long term that comes to fully offset the higher cost of treatment compared to the other options. So both varenicline monotherapy as associated with NRT have average costs of $€ 2.491,21$ and $€ 2.432,22$ per patient who quit smoking compared to the other options with Bupropion and TSN $4.136,55 €$ or drug treatment to $5.783,88 €$ in a perspective of two years.

\section{Discussion}

This study shows the important dropout rate that occurred during these two years of review, as only $66.7 \%$ of patients initially referred to the consultation came to the same. Furthermore, of those who came, left $50.3 \%$ of patients, so finally they started treatment only $33 \%$ of the total of the initial sample. Perhaps this is related to the fact that many of the patients are sent to the query does not request voluntarily, but are 
Citation: Lopez PJT, Grdoy R, Callejas FJ, Tornero Al, Montes JAR, et al. (2016) Pharmacoeconomic Analysis of the Therapies Used in the Treatment of Smoking in a Specialized Unit. J Pulm Respir Med 6: 347. doi:10.4172/2161-105X.1000347

Page 4 of 6

\begin{tabular}{|c|c|c|c|}
\hline & Varenicline & Varenicline+NRT & Bupropión+NRT \\
\hline Cost tto. $(€)$ & 360,68 & 515,96 & 309,9 \\
\hline Costs médical visits $(€)$ & 291,78 & 291,78 & 291,78 \\
\hline patients successfully & 33 & 65 & 8 \\
\hline Patients with relapsing & 93 & 130 & 47 \\
\hline Total cost treatment & $82.209,96$ & $157.509,30$ & $33.092,4$ \\
\hline Rate C/E & $2.491,21$ & $2.423,22$ & $4.136,55$ \\
\hline
\end{tabular}

Table 4: Pharmacoeconomic analysis study.

referred by their specialist given the severity of the pathology present and can be aggravated by the consumption of snuff or well attended by family pressures. On occasion, although to a much lesser extent, patients expressed at the first consultation difficulties to attend it due to incompatibility of schedule, displacement problems, among others, and in any other single occasion by patients decided not to start therapy was the high price of treatments used for detoxification and lack of funding by the health system (with after two years collected in this study date, but not currently on the delicate economic situation in which we find today, the SESCAM funded treatment for all workers belonging to such health system and teachers, for the exemplary effect of both groups [1418]. All these things have classified in Figure 2, as personal causes.

In our study it should be noted that $100 \%$ of patients received treatment in individualized format and in all psychological cognitive behavioral therapy was used. All meta-analyzes agree that the efficacy of treatment of smoking is independent of the format in which ofrezca [7,19-25].

Regarding the treatment prescribed in our sample, it should be noted that $32.7 \%$ of patients did not receive drug treatment [22-24].

The prescription of either drug treatment was based on the clinical characteristics of the patient, the extent and severity of smoking and personal preferences of each patient smoking [7,26-30]. The Spanish Respiratory Society SRS guidelines are always followed to try the dose and time of use of pharmacological treatments indicated [21,26].

NRT was the most used therapy, either in the form of gum, patches or in combination with varenicline by $34,5 \%$ of the sample, followed by varenicline $(22.9 \%)$ and, finally, bupropion $(9.8 \%)$. In our study, $27.7 \%$ of patients who received treatment were successful in smoking cessation. Considering only patients who started treatment, rates of continuous abstinence at 3, 6 and 9 months were $48.6 \%, 34.2 \%$ and $29.1 \%$, respectively.

Some of the variables associated with time of abstinence in this study were receiving no medical treatment or to stop smoking and type thereof (NRT, varenicline or bupropion) and the amount of consumption of tobacco [15-19].

As previously mentioned, the use of combination therapy in smoking cessation multiplied by 1.7 the chances of success compared to those who only receive psycology support [22-26].

Varenicline was the highest pharmacological treatment success rate achieved (26\%), although higher success rates occurred when treatment was combined with VRN and TSN (33\%). In any case, only he found statistical difference for Varenicline (26\%) compared to no treatment (4.4\%), with 99\% confidence, and for NRT and Bupropion (14.5\%) compared to no treatment, with $96 \%$ confidence, so it is possible that the large percentage of success with NRT+VRN and is due to chance. Strong correlation was also found most likely to succeed with the treatment of VRN and NRT, followed by varenicline.

As relapses in our sample, the majority of them occurred mainly

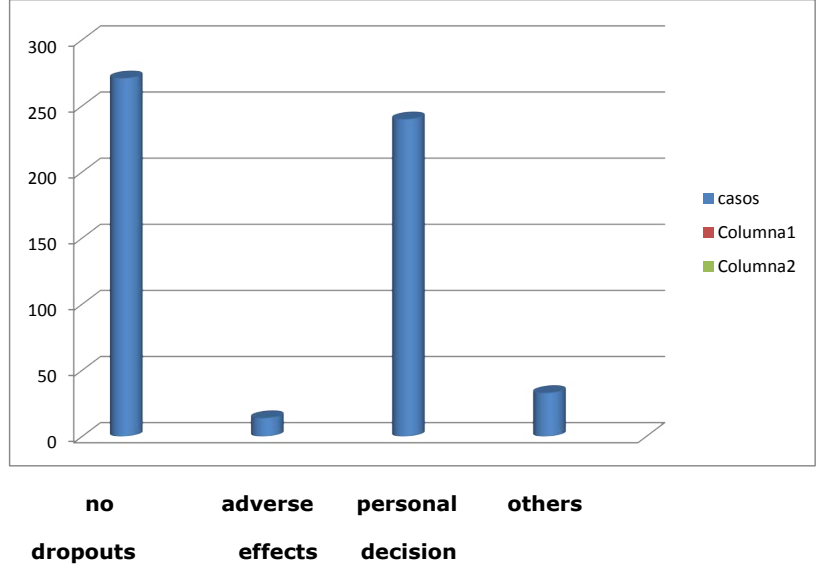

Figure 2: Discontinuations and its causes.

during the first three months $(22.3 \%)$, as in other series [27,28].

The scientific evidence available allow considered as first-line drugs for smoking cessation nicotine replacement therapy in its different presentations (NRT), bupropion and varenicline. The indication should be evaluated in smokers who have expressed a desire to quit smoking; they are in the preparation stage/action and make a serious attempt with a consumption of 10 or more cigarettes per day [29-32].

All three should be prescribed in a regulated program of addiction treatment, in which the smoker sets a date that will stop smoking completely and will have the support needed care. These drugs have contraindications and special situations indication should be properly evaluated by a medical professional [33-35].

Our pharmacoeconomic study shows that varenicline two options have proven to be the most cost-effective therapy of the 4 options used in the treatment to quit smoking in our unit, both used as monotherapy or with NRT complement ( 2491.21 to $2423.22 €$ per patient who quit smoking), although this costs outweigh the increased success rate significantly reduces the cost/effectiveness ratio.

The results of this study show similar to other studies pattern on this topic conducted in our country to assess the efficiency of different strategies to stop smoking, with the advantage that in this study real data is used in clinical practice [31-35].

Drug therapy is considered an adjunct motivational support, especially useful in the early stages of intervention to deal with withdrawal symptoms and cravings. The scientific evidence on the effectiveness of first-line drugs is based on high-quality randomized controlled trials. However, it is necessary to have quality information on the effectiveness medium and long-term or (maintenance of abstinence in more than 1 year periods), and global impact at the population level 
increased use of drug therapy on population rates smoking cessation and consolidation of abstinence. In this sense, it will be useful evidence provided in the analysis of the results of treatment services program implemented in our unit and will soon follow-up results published 6 years.

In article a limited vision of a chronic pathology addictive as smoking in a short time two years ago. Therefore the researchers intend to follow at 5 and 10 years to have a more complete vision.

Smokers who want to quit smoking should be able to access the most appropriate to their individual needs and characteristics treatment.

The systematic recording of smoking status in the medical history of each patient and opportunistic smoking cessation should be a widespread routine practice in the field of Primary Health Care, which is one of the most efficient approaches medical advices. It would be desirable enhance the provision of necessary resources to health professionals to respond adequately to the growing demand for treatment. There are already excellent guides to provide proper medical advice, as well as practical guides and self-help manuals to quit, published in Spain [32-38].

\section{References}

1. González-Enríquez J, Villar-Alvarez F, Banegas-Banegas JR, RodríguezArtalejo F, Martín Moreno JM (1997) Tendencia de la mortalidad atribuible al tabaquismo en España, 1978-1992: 600.000 muertes en 15 años. Med Clin (Barc) 109: 577-582.

2. Taylor WC, Pass TM, Shepard DS, Komaroff AL (1987) Cholesterol reduction and life expectancy. A model incorporating multiple risk factors. Ann Intern Med 106: 605-614.

3. Becoña-Iglesias E (Coord) (1998) Libro blanco sobre el tabaquismo en España. Barcelona: Glosa Ediciones.

4. Lopez AD, Collishaw NE, Piha T (1994) A descriptive model of the cigarette epidemic in developed countries. Tob Control 3: 242-247.

5. Villalbí JR (1995) Tabaquismo. En: Navarro C, Cabasés JM, Tormo JM. La salud y el sistema sanitario en España. Informe SESPAS 1995; Barcelona: SG Editores pp: 83-89.

6. Kuulasmaa K, Tunstall-Pedoe H, Dobson A, Fortmann S, Sans S, et al (2000) Estimation of contribution of changes in classic risk factors to trends in coronary-event rates across the WHO MONICA Project populations. Lancet 355: $675-687$.

7. Fernández E, Fu M, Pascual JA, López MJ, Pérez-Ríos M, et al. (2009) Impact of the Spanish smoking law on exposure to second-hand smoke and respiratory health in hospitality workers: a cohort study. PloS One 4: 4244-4248.

8. Villalbí JR, Barniol J, Nebot M, Díez E, Ballestín M (1999) [Trends in smoking among school children: Barcelona, 1987-1996]. Aten Primaria 23: 359-362.

9. Barrueco M, Hernández-Mezquita MA, Torrecilla M (2003) Manual de Prevención y Tratamiento del tabaquismo (2nd edn.) Majadahonda (Madrid): Ergon.

10. A g e $\mathrm{n}$ cy for Health Care Po I i cy, Research on Smoking Cessation (1996) The A g e $\mathrm{n}$ cy for Health Care Policy and Research on Smoking Cessation Clinical Practice Guideline. JAMA 275: 1270-1280

11. Alonso Gordo JM, Magro Pretejer R, Martínez Pérez JA, Sanz Bonacho N (1998) Tabaco y Atención Primaria. En: Libro Blanco del tabaquismo en España. C ap. 12. Comité Nacional para la Prevención del Tabaquismo. Barcelona: Glosa pp: 211-225.

12. Nebot M, Cabezas C, Oller M, Moreno F, Rodrigo J, et al. (1990) [Medica counseling, nursing counseling, and nicotine chewing gum for smoking cessation in primary care]. Med Clin (Barc) 95: 57-61.

13. Martín-Cantera C, Cordoba-García R, Jané-Julio C, Nebot-Adell M, GalanHerrea S, et al. (1997) Evaluación a medio plazo de un programa de ayuda a los fumadores. Med Clin (Barc) 109: 744-748.

14. Brotons C, Iglesias M, Martin-Zurro A, Martin-Rabadan M, Gene J (1996) Evaluation of preventive and health promotion activities in 166 primary care practices in Spain. The Coordinating Group For Prevention and Health Promotion in Primary Care in Spain. Fam Pract 13: 144-151.

15. Nebot M, Borrell C, Ballestín M, Villalbí JR (1996) [Prevalence and characteristics associated with tobacco use in a general population in Barcelona from 1983 to 1992]. Rev Clin Esp 196: 359-364.

16. Banegas JR, Díez L, Bañuelos B, González J, Martín-Moreno JM, et al. (2010) La mortalidad atribuible al consumo de tabaco en España en 2006. Med Clin (Barc) 136: 97-102.

17. Gorgojo Jiménez L, González Enríquez J, Salvador Llivina T (2003) Evaluación de la eficacia, efectividad y coste-efectividad de los distintos abordajes terapéuticos para dejar de fumar. AETS - Instituto de Salud Carlos III.

18. Jorenby DE, Hays JT, Rigotti NA, Azoulay S, Watsky EJ, et al. (2006) Efficacy of varenicline, an alpha4beta2 nicotinic acetylcholine receptor partial agonist, vs placebo or sustained-release bupropion for smoking cessation: a randomized controlled trial. JAMA 296: 56-63.

19. Silagy C, Lancaster T, Stead L, Mant D, Fowler G (2004) Nicotine replacement therapy for smoking cessation. Cochrane Database Syst Rev.

20. Gil E, González J, Villar F (1998) Informe sobre la salud de los españoles: 1998. Madrid: Ministerio de Sanidad y Consumo pp: 182-191.

21. Pardell H, Saltó E, Canela J, Salleras $L$ (1993) Smoking cessation rates after three months treatment with nicotine patch among health professionals in Catalonia, Spain. Int J Smoking Cessation 2: 35-37.

22. Moragues I, Nebot M, Muñoz M, Ballestín M, Saltó E (1999) [Evaluation of a community intervention program ("Quit and Win") for smoking cessation]. Gac Sanit 13: 456-461

23. Becoña E, Vázquez FL, Míguez MC (1996) The smoking cessation program of the University of Santiago de Compostela 1984-96. En: Smoke-free Europe. Helsinki: Finnish Centre for Health Education p: 117.

24. Jiménez Ruiz CA, Solano Reina S, González de Vega JM, Ruiz Pardo MJ, Flórez Martín S, et al. (1999) [Guidelines for the treatment of smoking. The Working Group for the Treatment of Smoking of the Smoking Area. SEPAR (Sociedad Española de Neumología y Cirugía Torácica)]. Arch Bronconeumol 35: 499-506.

25. Jiménez-Ruiz CA, de Granda Orive Jl, Solano Reina S, Carrión Valero F, Romero Palacios P, et al. (2003) [Recommendations on the treatment of tobacco dependence]. Arch Bronconeumol 39: 514-523.

26. Rodríguez Hermosa JL, Calle Rubio M, Álvarez-Sala Walther JL (2008) Módulo 8: Tratamiento I. Unidad 7. Bupropión. En: Máster en Prevención y Tratamiento del Tabaquismo. Instituto for Lifelong Learning. Universitat de Barcelona. Edición UB virtual.

27. Niaura R, Hays JT, Jorenby DE, Leone FT, Pappas JE, et al. (2008) The efficacy and safety of varenicline for smoking cessation using a flexible dosing strategy in adult smokers: a randomized controlled trial. Curr Med Res Op 24: 1931-1941.

28. Hays JT, Ebbert JO (2010) Adverse effects and tolerability of medications for the treatment of tobacco use and dependence. Drugs 70: 2357-2372.

29. Stead LF, Lancaster T (2005) Group behavior therapy programs for smoking cessation. Cochrane Database Syst Rev 18.

30. Jiménez-Ruiz CA, Riesco Miranda JA, Ramos Pinedo A, Barrueco Ferrero $M$ Solano Reina S, et al. (2008) [Recommendations for pharmacological tobacco cessation treatments: proposals for financing]. Arch Bronconeumol 44: 213 219 .

31. Pascual-Lledó JF, De la Cruz-Amorós E, Bustamante-Navarro $R$, BuadesSánchez MR, Contreras-Santos C, et al. (2006) [Smoking cessation after 12 months follow-up at a smoking cessation unit]. Med Clin (Barc) 126: 601-606.

32. Bauld L, Judge K, Platt S (2007) Assessing the impact of smoking cessation services on reducing health inequalities in England: observational study. Tob Control 16: 400-404.

33. Woolacott N, Jones L, Forbes C, Mather L, Sowden A, et al. (2002) NHS Centre for Reviews and Dissemination. A rapid and systematic review of the clinical and cost effectiveness of bupropion SR and nicotine replacement therapy (NRT) for smoking cessation. The National Institute for Clinical Excellence, York: University of York.

34. [No authors listed] (1999) Curbing the epidemic: governments and the economics of tobacco control. The World Bank. Tob Control 8: 196-201. 
Citation: Lopez PJT, Grdoy R, Callejas FJ, Tornero Al, Montes JAR, et al. (2016) Pharmacoeconomic Analysis of the Therapies Used in the Treatment of Smoking in a Specialized Unit. J Pulm Respir Med 6: 347. doi:10.4172/2161-105X.1000347

35. Fernández de Bobadilla Osorio J, Sánchez-Maestre C, Brosa Riestra M, Arroyo O, Sanz de Burgoa V, et al. (2008) Cost effectiveness analysis of varenicline (Champix $\left.{ }^{\circledR}\right)$ for the treatment of smoking in Spain. An. Med. Interna (Madrid) 25: $342-348$

36. Drummond MF, O'Brien BJ, Stoddart GL, Torrance GW (2005) Métodos para la evaluación económica de los programas de asistencia sanitaria. Ediciones
Díaz de Santos S.A., Madrid.

37. Cahill K, Stead LF, Lancaster T (2007) Nicotine receptor partial agonists for smoking cessation (Review). Cochrane Database Syst Rev 24.

38. Sacristán JA, Oliva J, Del Llano J, Prieto L, Pinto JL (2002) [What is an efficient health technology in Spain?]. Gac Sanit 16: 334-343. 